\title{
Comparative Assessment of Different Optimization Techniques for Turning Operations
}

\section{تقييم مقارن لطرق التحسين المختلفة لعمليات الخراطة}

\author{
Elsanabary S. ${ }^{1}$, Elkaseer A. ${ }^{2}$, Abd-Rabbo S. ${ }^{3}$, AbdElsalam M. ${ }^{4}$, \\ Abdou S. $^{5}$ \\ ${ }^{1}$ Prod. Eng. \& Mech. Design Depart., Faculty of Eng., Port Said Uni. \\ Email: samarelsanabary@yahoo.com \\ ${ }^{2}$ Lecturer of Production Eng., Faculty of Eng., Port Said University. \\ Email: elkaseeram@gmail.com \\ ${ }^{3}$ Prof. of Production Eng., Faculty of Eng., Shoubra, Benha University. \\ Email: saberabdrabbo@yahoo.com \\ ${ }^{4}$ Prof. of Production Eng., Faculty of Eng., Ain Shams University. \\ Email: msalam200042@yahoo.com \\ ${ }^{5}$ Prof. of Production Technology, Faculty of Eng., Port Said University. \\ Email: smiabdou@hotmail.com
}

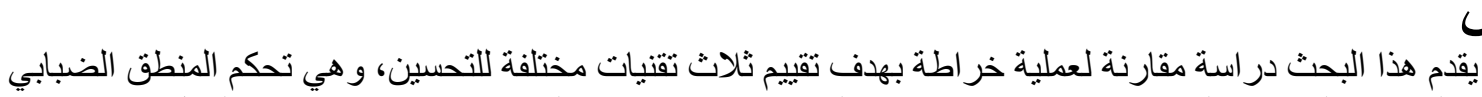

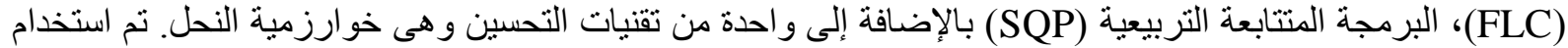

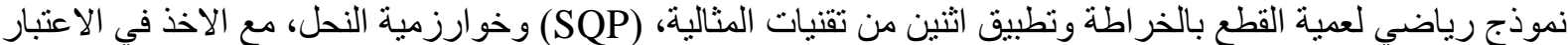

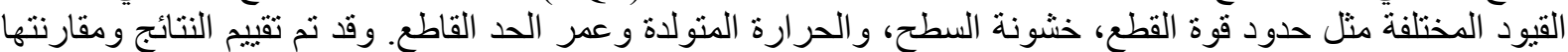

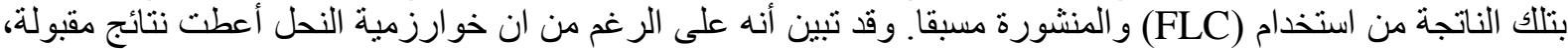

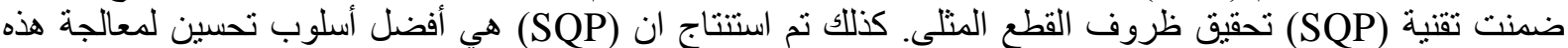
المشكلة، خاصة عند مقارنتها مع أداء الطريقتنين الأخرتين اللتنين تم بحثها في إطار هذه الدر استة
\end{abstract}

\begin{abstract}
This paper presents a comparative study that was conducted aiming at evaluating three different optimization techniques; namely, linguistic Fuzzy Logic Control (FLC), Sequential Quadratic Programming (SQP), and the Bees Algorithm. Initially, a well-constructed deterministic model of the turning operation was utilized to feed two optimization techniques, (SQP) and the Bees Algorithm. The results were assessed and compared with those already obtained using (FLC) method that was published in the literature. The study outcomes revealed that, although The Bees Algorithm gave acceptable output, the (SQP) technique identified the optimal cutting conditions. As a result, one can argue that the (SQP) is the best technique to tackle such deterministic optimization problem. This is especially true when compared with the performance of the other two methods examined within this study.
\end{abstract}

\section{Keyword}

Optimization Techniques, Turning Model, Linguistic Fuzzy Logic Control (FLC), Sequential Quadratic Programming (SQP), the Bees Algorithm

\section{Introduction}

Nowadays, the philosophy of modern manufacturing technologies is to produce products in shorter time, with higher capabilities and at the lowest possible production cost. However, due to the dynamic processes and increase of the machining parameters, optimization of these production operations has become essential [1].

Due to the fact that, turning is one of the most important and widely used 
manufacturing processes in engineering industries, it is urgent to undertake a systematic study to maximize the performance of this technology. The study of turning focuses on the features of the cutting tool, the behavior of the workpiece materials, and machining parameters and their consequent effects on the process efficiency and output quality [1]. Optimization techniques play a significant role to improve the performance of the turning process. In particular, optimization of cutting parameters in machining processes is very important to produce high quality products and reduce the product costs $[2,3]$.

Several optimization studies to determine the optimal cutting parameters have been reported [3-12]. However, in order to utilize any optimization methodology, initially, reliable mathematical models have to be formulated to associate the cutting parameters with cutting performance. Once the reliable model for turning operations has been constructed, an optimization algorithm is then applied to the model for determining the optimal cutting parameters [4].

It's obvious that optimization of cutting parameters in turning operations is a fruitful field which has attracted researchers to carry out massive optimization trials to improve the process. The literature has shown that most of work carried out was mainly to evaluate the optimum cutting parameters; cutting speed, feed rate, and depth of cut. However, this was conducted without comprehensive considerations of the associated constraints. Especially, the effects of such constraints on the cutting performance such as cutting temperature, cutting forces, power consumption, tool life, and surface roughness has not been fully examined. It is worth emphasizing that detailed cutting model considering inclusive constraints is a complex problem and conducting proper optimization process of such problem is a challenging issue that still needs addressing. Thus, it's important to examine several types of optimization techniques on turning model to predict precisely the resulting effect on cutting performance. In this context, the aim of this research is to assess three different optimization techniques to tackle a general turning model to evaluate the optimum cutting conditions and study their effect on cutting performance.

The remainder of the paper is organized as follows. Firstly, the next section reports on the most related background and provides a specific review of the tuning models and optimization techniques. Secondly, the paper introduces the molding approach utilized to feed the different optimization methods. Thirdly, the following part explains the procedure followed to apply the three different types of optimization techniques on the turning model. Then, the results of the study are discussed paying more attention to carry out comparative analysis of the results of the three optimization methods. Finally, conclusions and perspective are given in the last section.

\section{Background \\ 2.1 Turning Model}

The pre-stage of applying any optimization strategy is to develop a reliable model that is able to comprehensively capture the effects of the governing parameters. The general analysis of the turning model is based on the popular economic criterion of minimum production time or maximum production rate or minimum cost per components. The constraints to be considered include the machine tool feed and speed limits, maximum power force, spindle torque, power constraints, the obtained surface roughness constraint, and the minimum tool-life limit that may be imposed by the production systems [3-12]. Arrazola et. al. [4] presented the state of art in predictive performance models for machining and scoped on the strengths and weaknesses of the models. The authors classified the modeling techniques into four different 
types such as analytical, numerical, empirical, and hybrid models. Many researchers worked on machining models to predict the machining performance, $\mathrm{Lu}$ et.al. [3], Alberti et.al. [12] used a classical machining economic model for minimizing the production cost, while Chiu et.al. [5] proposed a new multi pass (rough and finish) cutting model for dry turning processes. The proposed mathematical model contains the objective to minimizing the unit of production cost considering the dry effect. Also, a comprehensive set of practical machining constraints especially focusing on dry cutting conditions in several key elements such as the cutting force, cutting power, tool-chip interface temperature, and more importantly the tool life. For maximizing the production rate and minimizing the production cost. Lee et.al. [8] applied the mathematical model on multistage turning operations. Due to the importance of the surface roughness of the machining parts, the researchers try to predict the surface roughness generation by mathematical models. For example, Motorcu [9] developed second order regression model for predicting the surface roughness of AISI 8660 hardened alloy steels. The author concluded that the predicted values were very close to the experimental one for surface roughness.

\section{2optimization Techniques}

The aim of optimization technique is to provide optimal or near-optimal solution(s) to the overall optimization problem formulated. A large number of techniques has been developed by researchers to solve optimization problems, and may be classified as conventional and non-conventional optimization techniques as shown in Fig. (1). Many researchers applied several optimization techniques on their model to find the optimum solution. For minimization the production cost, Lee et. al. [8] investigated the optimal cutting parameters of multi-stage turning operation for maximizing the production rate. The authors used a sequential quadratic programming method for optimizing the cutting parameters as a state-of-the-art in non-linear programming methods. Abburi et. al. [10] developed a Real Genetic Algorithm (RGA) and Sequential Quadratic Programming (SQP) for minimizing the production time of multiobjective optimization of multi-pass turning process. Munawar et. al. [11] presented an experiment work performed on AISI 1040 carbon steel for optimizing the surface roughness $(\mathrm{Ra})$ by taken into account the effect of machine tool vibration using Taguchi method. The authors showed that a machine tool with low vibration amplitude, large tool nose radius, and low feed rate produced better surface roughness. Saravanan [6] applied Simulated Annealing (SA) and Genetic Algorithm (GA) for obtaining the optimum cutting conditions for minimizing the production cost of a cylindrical stock machined on multi pass (rough and finish) turning process. The authors concluded that (SA) has better results than (GA).

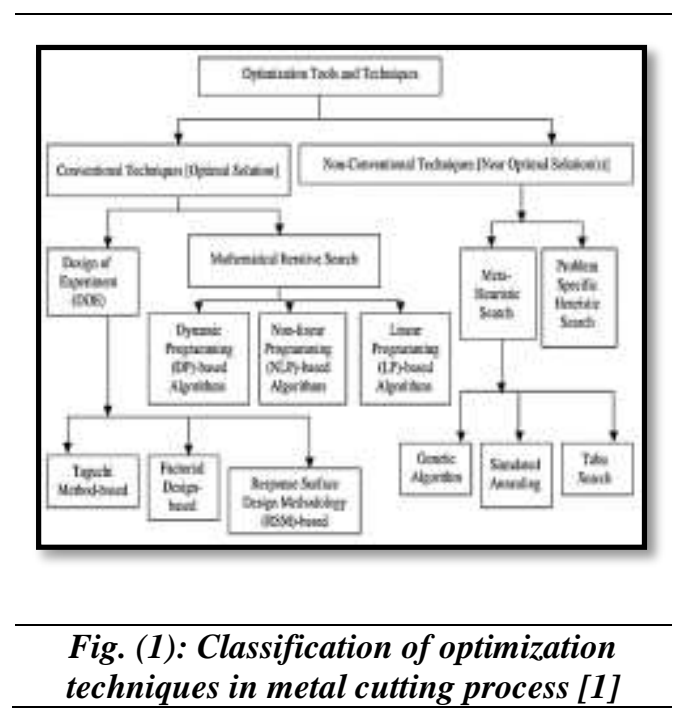

\subsubsection{Lingiustic Fuzzy Logic Control (Flc) Approach}

Fuzzy logic control (FLC) approach uses fuzzy sets to represent inputs and outputs and it based on an input/output or block box relationship [13]. Fuzzy logic depends on the expert system knowledge; the approach converts process into a group of linguistic fuzzy set rules. This 
optimization technique applied to the mentioned turning model for obtains the objective function. Alberti et. al. [12] proposed a new optimization approach which used a fuzzy possibalistic linear formulation for optimizing the cutting parameters in multi pass machining. The authors concluded that fuzzy possibilistic formulation with the genetic algorithm fit very well to machining economics problems and can be obtained in one step. Researchers tried to find the optimal cutting conditions by using (FLC), based on the knowledge and a linguistic fuzzy (if then role); the optimum machining conditions via input cutting constraints for both force and temperature were used to support a decision of machining parameters [13]. On the other hand, the fuzzy output cutting speed values had good correlation with the cutting temperature at different values of depth of cut.

\subsubsection{Sequential Quadratic Programming (Sqp)}

In this section, the optimum cutting conditions in the turning model can be obtained by using a special optimization tool box in MATLAB, which has wide range of capabilities to tackle different optimization problems such as linear, nonlinear, quadratic, least square, and mixedinteger linear [14]. The methodology of the minimization function, fmincon, function is a reliable tool to solve the minimum of a constrained non-linear objective function of several variables starting at user specified initial estimate. fmincon uses (SQP) method with the active set optimization algorithm and contains a collection of algorithms that govern how a local minimum point is reached. The algorithms are Active-set (AS), (SQP), and Interior-point (IP). Also, fmincon provides to solve functions linear or nonlinear, constrained or unconstrained problems [15, 16]. Kurdi et. al. [17] introduced a semianalytical modeling and multi-objective optimization using fmincon optimization function to find the optimum spindle speed and axial depth of cut of milling process.
The authors calculated the trade-off curve of metal removal rate (MRR) and surface location error (SLE). The authors concluded that the maximum (MRR) did not denote any chatter and the measured (SLE) did not show high sensitivity to spindle speed variation.

\subsubsection{The Bees Algorithm}

The Bees algorithm is a nature inspired algorithm based on the intelligent foraging behavior of honey bee swarm to find the optimum solution. The Bees algorithm describes the foraging behavior, learning, memorizing and information sharing characteristics of honeybees. In the basic of Bees algorithm is combined of random and neighborhood search [18, 19].Many researchers were interested in Bees Algorithm for optimization technique; Yildiz [7] developed an optimization approach for minimizing the cost and find the optimum cutting conditions in multi-pass turning operations based on artificial bee colony algorithm. The Bees Algorithm is intended to mimicry the behavior of honey bees when foraging. Basically, individuals from a bee colony start to search randomly for good patches around the hive. When they came back, they direct other bees to the patch they have found. Each recruiter bee performs a dance, called the waggle dance, which indicates the rich of the source.

\section{Modeling Approach}

Prior to conducting the comparison between the three optimization techniques, it was urgent to identify well-constructed turning model to feed the optimization techniques for comparative assessment. This section contains the turning model with objective function and related constraints to be used as a bench mark [13].

\subsection{Objective Function}

The objective function $\mathrm{W}(\mathrm{x})$ of turning model used to minimize the production time can be expressed in Eq. (1). In this model $\mathrm{W}(\mathrm{x})$ used to minimize 
the production time (min.) and it's defined as the summation of holding, machining and tool change time. The total production cycle time for one part is composed of three items, i.e., part handling time $\left(t_{h}\right)$, machining time $\left(t_{m}\right)$, and tool change time $\left(\mathrm{t}_{\mathrm{c}}\right)$ and tool life $(\mathrm{T})$ can be expressed in Eq. (1-2):[13]

$$
\begin{aligned}
& \mathrm{W}(\mathrm{x})=t_{h}+n_{p} * t_{m}+t_{c} * \frac{n_{p} * t_{m}}{T} \\
& n_{p}=\frac{\text { The total machiningallowanceto be removed }(H)}{\text { Depth of } \operatorname{cut}(a)}
\end{aligned}
$$

The machining time $\left(t_{m}\right)$ is expressed in Eq. (3), as a function of work piece dimensions length (L) and diameter (D), cutting speed (V) and feed rate (f);

$$
t_{m}=\frac{\pi D L}{1000 V f}
$$

\subsection{Constraints}

The constraints considered [13] include the machine tool feed and speed limits, maximum power force, spindle torque, power constraints, the component surface roughness constraint, and the minimum and maximum tool-life limits that may be imposed by the production systems.The tool life (T) (min.) constraint is taken as the following Eq. (4);

$T=\frac{C_{v}^{\frac{1}{m}}}{V^{\frac{1}{m}} f^{\frac{p}{m} a^{\frac{q}{m}}}} \geq T_{o p t}-\Delta T$

where; $\mathrm{C}_{\mathrm{v}}, \mathrm{m}, \mathrm{p}, \mathrm{q}$ are constant values,

$T_{\text {opt }}=\frac{\text { tool cost per cutting edge }\left(C_{2}\right)}{\text { machine and labor } h r \text { per cost }\left(C_{1}\right)}\left(\frac{1-m}{m}\right) * 60$

and $\Delta \mathrm{T}$ is uncertainty of tool life. The chip tool interference temperature constraint $\left(\theta_{C}\right)\left({ }^{\circ} \mathrm{C}\right)$ is taken as the following Eq. (5);

$\theta_{c}=\beta_{0} V^{\beta_{1}} f^{\beta_{2}} a^{\beta_{3}} \leq \theta_{U}+\Delta \theta$

where; $\beta_{i}=(i=0,1,2,3)$ are empirical parameters, $\theta_{U}$ is the maximum allowable temperature and $\Delta \theta$ is uncertainty of chip tool interference temperature by which the boundary is moved and
The cutting force $(\mathrm{Fc})(\mathrm{Kg})$ constraint is taken as the following Eq. (6);

$F_{c}=\frac{K_{1} K_{2}}{(\sin \chi)^{1-x}} a f^{x} V^{x 1} \leq F_{c u}+\Delta F_{c}$

where; $\mathrm{K}_{1}, \mathrm{~K}_{2}, \mathrm{x}, \mathrm{x}_{1}$ are constant values, $F_{c u}$ is the maximum force and $\Delta F_{c}$ is uncertainty of the cutting force by which the boundary is moved.

The power consumption $\left(P_{c}\right) \quad(\mathrm{KW})$ constraint in the turning operation is given by Eq. (7);

$P_{c}=\frac{F_{c} V}{60000 \eta} \leq P_{m}+\Delta P$

where $P_{m}$ is the input power, $\Delta P$ is the uncertainty of cutting power and $\eta$ is the mechanical efficiency.

The limitation of surface roughness is necessary to insure the quality of machining operation, the empirical equation of the surface roughness $\left(R_{z}\right)$ $(\mu \mathrm{m})$ constraint is given by the following Eq. (8);

$R_{z}=K V^{\alpha_{1}} f^{\alpha_{2}} a^{\alpha_{3}} \leq R_{p}+\Delta R$

where; K, $\alpha_{1}, \alpha_{2}$ and $\alpha_{3}$ are the empirical parameters, $R_{p}$ is the allowable surface roughness and $\Delta R$ is the uncertainty of surface roughness. The upper and lower bounds to limit the value of the cutting speed, feed and depth of cut defined as the following Eqs. (9-11); [13]

$V_{\min } \leq V \leq V_{\max }$

$f_{\min } \leq f \leq f_{\max }$

$a_{\min } \leq a \leq a_{\max }$

The performance of the three optimization techniques will be assessed; the work conducted with this paper includes applying only (SQP) in addition to the Bees algorithm. The results obtained will be compared with those already reported using (FLC) [13]. As a result, to keep the same modeling conditions, the uncertainty values of the cutting parameters will be taken compared with results of (FLC) [13]. 


\section{Applied Optimization}

\section{Techniques}

\subsection{Linguistic Fuzzy Logic Control (Flc) Approach}

The optimum cutting conditions considering the uncertainty values of constraints by using (FLC) on the previous turning model [13].

\subsection{Sequential Quadratic Programming (Sqp)}

The function fmincon applied on turning model to find the optimum cutting conditions. First of all, it is important to define the objective function as given in the following Eq. (12); [13]

$W(x)=1+\left[\frac{6}{x_{3}} * \frac{\pi * 50 * 300}{1000 * x_{1} * x_{2}}\right]+\left[\frac{\left[\frac{6}{x_{3}} * \frac{\pi * 50 * 300}{1000 * x_{1} * x_{2}}\right]}{\left[\frac{7^{5}}{x_{1}^{5} * x_{2}^{2} * x_{3}^{0.75}}\right]}\right]$

where; $\mathrm{W}(\mathrm{x})$ is the objective function of minimizing the production time, the cutting speed is $\mathrm{x}_{1}$, feed is $\mathrm{x}_{2}$ and depth of cut is $\mathrm{x}_{3}$. Then , the constraints considered include the limits of cutting speed, machine tool feed, depth of cut limits, maximum power force constraint, power consumption constraint, the surface roughness constraint, and the allowable tool-life limits. The procedure followed to undertake the (SQP) algorithm is as shown in Fig. (2).

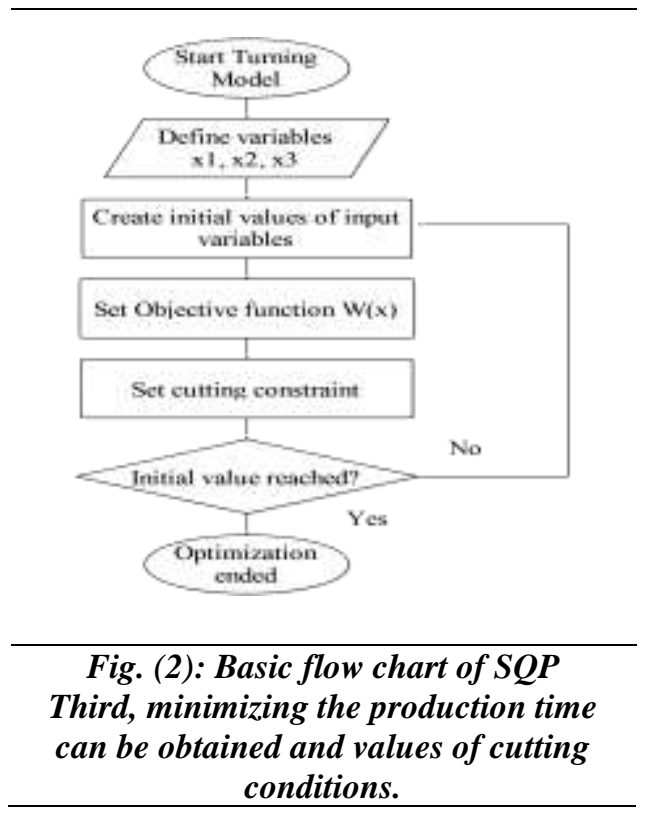

\subsection{The Bees Algorithm}

The optimal cutting condition can be determined using the Bees algorithm to obtain the minimum production time. First of all, the Bees algorithm starts to find the optimum condition by setting an initial random values of $x(1), x(2)$, and $x(3)$ and applied them on the fitness function $\mathrm{W}(\mathrm{x})$. After that, the algorithm tries to find the optimum values in neighborhood sits and compare it with the initial one to get which site get an optimum fitness function. Bees Algorithm then tries to evaluate between sites to find the optimum solution, based on the program stopping criteria. The Bees Algorithm then stops its Iterations and the best solution is presents. The following pseudo code shown in Fig. (3) for minimizing the production time and find the optimum cutting conditions.

Pseudo code of basic Bees Algorithm
1. Initialize population with random $\mathrm{x}(1), \mathrm{x}(2)$, and
$\mathrm{x}(3)$.
2. Evaluate fitness $\left[\mathrm{W}(\mathrm{x})=1+\left[\frac{6}{x_{3}} * \frac{\pi * 50 * 300}{1000 * x_{1} * x_{2}}\right]+\right.$
$\left[\frac{\left[\frac{6}{x_{3}} * \frac{\pi * 50 * 300}{1000 * x_{1} * x_{2}}\right]}{\left[\frac{7^{5}}{x_{1}^{5} * x_{2}^{2} * x_{3}^{0.75}}\right]}\right]$ of the population.
3. While (stopping criterion not met)
/Forming new population.
4. Select sites of $\mathrm{x}(1), \mathrm{x}(2), \mathrm{x}(3)$ with the best solution
$\mathrm{W}(\mathrm{x})$ for neighborhood search.
5. Recruit bees for selected sites (more bees for best
e sites) and evaluate $\mathrm{W}(\mathrm{x})$.
6. Select the fittest bee from each patch.
7. Assign remaining bees to search randomly of
$\mathrm{x}(1), \mathrm{x}(2)$,and $\mathrm{x}(3)$ and evaluate their fitness's $\mathrm{W}(\mathrm{x})$.
8. End While.
Fig. (3): Pseudo code of minimum
production time W(x)

\section{Results and Discussions}

The results of applying three different types of optimization technique on general turning model, under uncertainty constraints are presented in this section. However, this part of study pays more attention to undertake impartial comparison of the achievable results of cutting variables. 


\subsection{Comparison Between Optimum Cutting Condition With Optimization Techniques}

After applying two different types of optimization techniques and then comparing the results of production time value between (FLC) approach, (SQP) and Bees Algorithm, the results are illustrated in Table (1). This comparison has applied on the same turning model considering the same uncertainty values of constraints. The minimum production time obtained when applying (SQP) and Bees Algorithm were $308 \mathrm{~min}$ and $359 \mathrm{~min}$, respectively. However, (FLC) approach gave $1.868^{*} 10^{5}$ min which is unreliable for production time for machining parts.

Table 1: Optimum Cutting Conditions

\begin{tabular}{|c|c|c|c|}
\hline $\begin{array}{c}\text { Cutting } \\
\text { Conditions }\end{array}$ & (FLC) & (SQP) & $\begin{array}{c}\text { Bees } \\
\text { Algorithm }\end{array}$ \\
\hline $\begin{array}{c}\text { Objective } \\
\text { Function } \\
\text { W(x) (min) }\end{array}$ & $1.868 * 10^{5}$ & 308 & 359 \\
\hline $\begin{array}{c}\text { Cutting } \\
\text { Velocity } \\
\text { (V) } \\
\text { (m/min) }\end{array}$ & 88 & 18 & 15 \\
\hline $\begin{array}{c}\text { Feed Rate } \\
\text { (f) } \\
\text { (mm/rev) }\end{array}$ & 0.29 & 0.05 & 0.06 \\
\hline $\begin{array}{c}\text { Depth of } \\
\text { Cut (a) } \\
\text { (mm) }\end{array}$ & 6 & 1.4 & 1.02 \\
\hline
\end{tabular}

In this context, the minimum value of best production time has optimum cutting condition; cutting speed, feed rate and depth of cut. First, the optimum cutting speed showed that the value of cutting speed has recorded an optimum value of 18 $\mathrm{m} / \mathrm{min}$. for (SQP) method. On the other hand, (FLC) approach and the Bees algorithm and gave approximate values of 88 and $15 \mathrm{~m} / \mathrm{min}$., respectively. Second, the optimum feed rate has recorded an optimum value of $0.05 \mathrm{~mm} / \mathrm{rev}$ and 0.06 $\mathrm{mm} / \mathrm{rev}$ for (SQP) and Bees Algorithm respectively. Also, (FLC) approach has an optimum feed rate at $0.29 \mathrm{~mm} / \mathrm{rev}$. Finally, the optimum depth of cut has an optimum value of $1.4 \mathrm{~mm}$ for (SQP) method. On the other hand, the value of depth of cut for (FLC) approach has value of $6 \mathrm{~mm}$ and Bees algorithm has a value of $1.02 \mathrm{~mm}$.

\subsection{Effect of Cutting Conditions On Cutting Performance}

This section presents a comparison between the three types of optimization techniques and the cutting performance such as cutting temperature, cutting force, power consumption, tool life, and surface roughness. The following comparison studied the effect of different cutting speed at altered depth of cut for constant feed rate for the three optimization techniques. First of all, the effect of cutting conditions on cutting temperature, as shown in Fig.(4), reveals that (FLC) gradually increased to reach $600^{\circ} \mathrm{C}$ at speed of 88 $\mathrm{m} / \mathrm{min}$. On the other hand, both (SQP) and Bees Algorithm followed almost the same trend of the cutting temperature with values of $280^{\circ} \mathrm{C}$ and $260^{\circ} \mathrm{C}$ at cutting speed of $18 \mathrm{~m} / \mathrm{min}$ and $15 \mathrm{~m} / \mathrm{min}$, respectively.

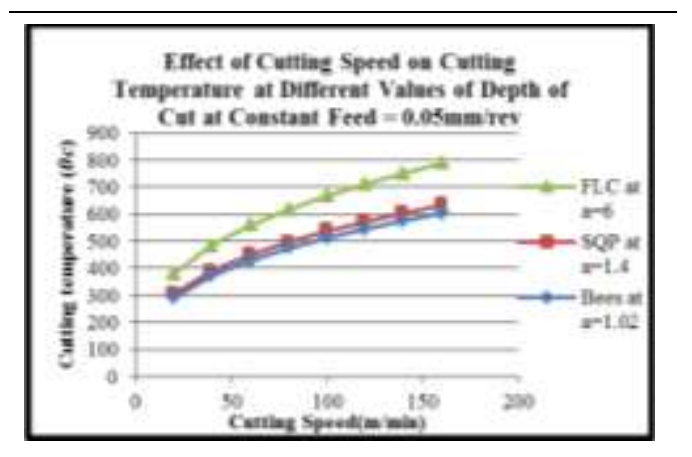

Fig. (4): Effect of identified cutting conditions on Cutting Temperature $\left(\theta_{c}\right)$

Secondly, Fig. (5) shows that there is a slight decrease on cutting force between (SQP) and Bees algorithm which resulted values of $100 \mathrm{Kg}$ and $70 \mathrm{Kg}$ at $18 \mathrm{~m} / \mathrm{min}$ and $15 \mathrm{~m} / \mathrm{min}$. respectively. On the other hand, (FLC) gave a high point reach to 240 $\mathrm{kg}$ at $88 \mathrm{~m} / \mathrm{min}$. Bees algorithm has lower cutting force than other techniques. 


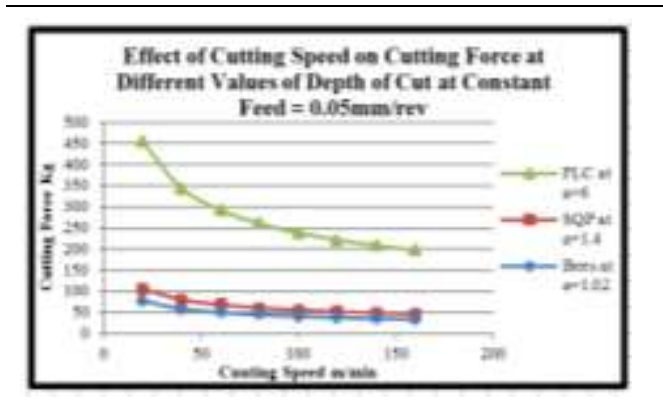

Fig. (5): Effect of identified cutting conditions on Cutting Force $\left(F_{c}\right)$

Thirdly, the power consumption used to machine the workpiece was $0.4 \mathrm{KW}$ when applying (FLC) at $88 \mathrm{~m} / \mathrm{min}$. as shown in Fig. (6), on the other hand, it needed only $0.026 \mathrm{KW}$ and $0.024 \mathrm{KW}$ when applying the other two techniques (SQP) and the Bees algorithm at $18 \mathrm{~m} / \mathrm{min}$ and $15 \mathrm{~m} / \mathrm{min}$ respectively. The effect of the identified cutting conditions on power consumption of Bees algorithm showed lower power consumption than the other techniques

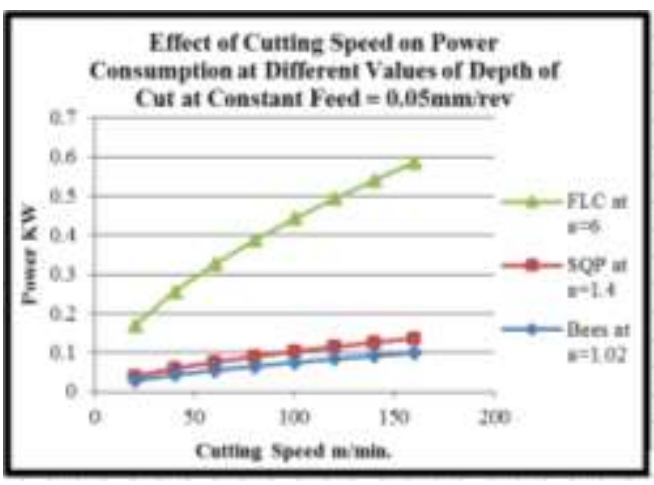

Fig. (6): Effect of identified cutting conditions on Power Consumption $\left(\boldsymbol{P}_{c}\right)$

Fourthly, surface roughness $\left(R_{z}\right)$ is one of the significant evaluations of the accuracy for the product. Fig. (7) shows that (SQP) and Bees Algorithm identified values associated with rough surface near to $1 \mu \mathrm{m}$. However, (FLC) has determined the optimum surface with value of $0.8 \mu \mathrm{m}$.

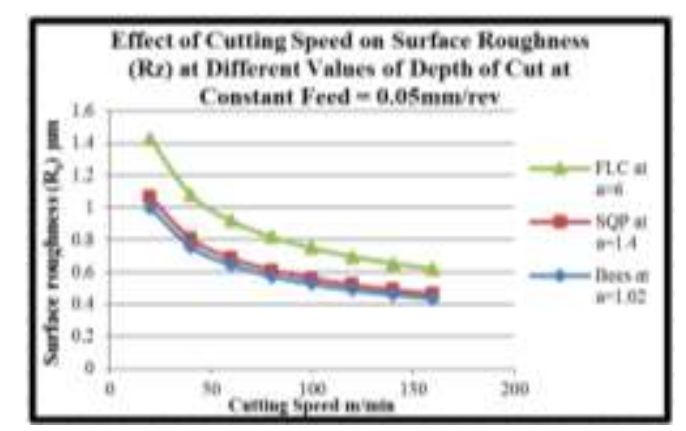

Fig. (7): Effect of identified cutting conditions on surface roughness $\left(R_{z}\right)$

Finally, Fig. (8) shows the effect of optimization techniques on tool life. Obviously, it revealed that (FLC) led to too short tool life of $5.3 * 10^{-4} \mathrm{~min}$. Conversely, (SQP) and Bees Algorithm resulted values associated with long tool life of 1.63 minute and $2 \mathrm{~min}$, respectively. This is attributed to the effect of low cutting speed which allows the tool to live longer time comparing with (FLC) that determined high cutting speed of $88 \mathrm{~m} / \mathrm{min}$.

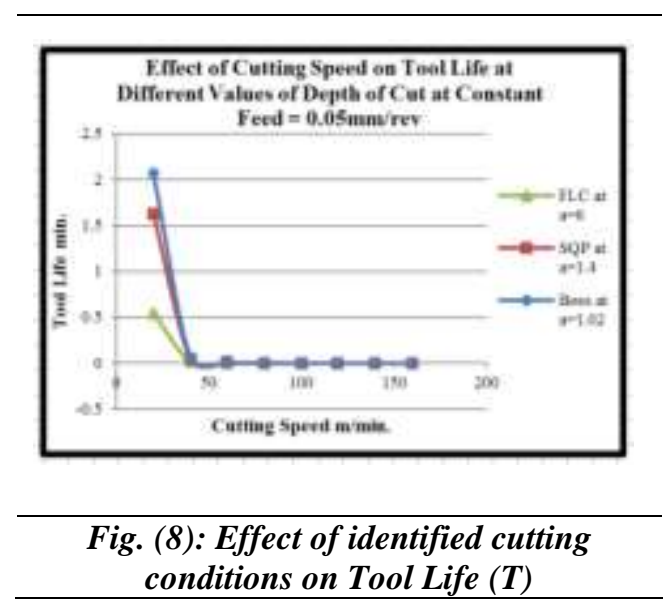

\section{Conclusion}

This paper has reported on a theoretical study undertaken to conduct a comparative assessment between different optimization techniques that were involved conventional and non-conventional techniques, (FLC), (SQP) and the Bees algorithm. Well-constructed turning model for minimizing the production time of unit 
part was optimized using the three techniques under the same constraints and uncertainty values. The aim was to identify the best minimum production time under uncertainty variables and the effect of optimum cutting conditions on cutting performance such as cutting temperature, cutting force, power consumption, tool life, and surface roughness.

Followings are some specific conclusions drawn based on the results of the carried out analysis.

- The comparison between three types of optimization techniques on turning model for obtaining the minimum production time under uncertainty constraints revealed that sequential quadratic programming (SQP) gave better results of minimum production time and cutting conditions than the other ones. However, the Bees Algorithm, as a powerful genetic algorithm provided very acceptable results. This especially valid in case of stochastic problems to be optimized.

- Fuzzy logic control led to very large production time because of the effect on high cutting speed on tool life, fuzzy logic control (FLC) resulted very high value, out of range, that negatively influence the cutting performance.

- The Bees algorithm has good effect on cutting temperature, cutting force, consumption power and tool life compared with other techniques.

- One can conclude that the difference between optimization techniques depends on the user needs. However, in this problem, (SQP) has needed the minimum time to reach the optimum solution compared with other techniques.

\section{Acknowledgment}

The authors gratefully acknowledge the support of Eng. Mohamed A. Negm for his support in conducting the programming part.

\section{Reference}

[1] Mukherjee I, Kumar Ray P,"A review of optimization techniques in metal cutting processes," Computers \& Industrial Engineering, (2006), 50, 15-34

[2] Yusup N, Zain A, Mohd Hashim S," Evolutionary techniques in optimizing machining parameters: Review and recent applications (2007-2011)," Expert Systems with Applications, (2012), 39, 9909-9927

[3] Lu K, Jing M, Zhang X and Liu H," Optimization of sequential subdivision of depth of cut in turning operations using dynamic programming," International Journal Advanced Manufacturing Technology, (2013), 68, 1733-1744

[4] Arrazola P.J.,Ozel T, Umbrello D, Davies M, and Jawahir I.S.," Recent advances in modelling of metal machining processes," CIRP Annals Manufacturing Technology, (2013), 62, 695-718

[5] Wang Y and Chiu Y,"An Evolutionary Strategy for Optimizing Multi-pass Turning Operation under Dry Machining Conditions," The 41st CIRP Conference on Manufacturing Systems, (2008), 381384

[6] Saravanan R, Asokan P and Vijayakumar K," Machining Parameters Optimisation for Turning Cylindrical Stock into a Continuous Finished Profile Using Genetic Algorithm (GA) and Simulated Annealing (SA) Int. J. Adv. Manuf. Technol., (2003), 21, pp:1-9

[7] Yildiz A,"Optimization of cutting parameters in multi-pass turning using artificial bee colony-based approach," Information Sciences,(2013), 220, pp: 399-407

[8] Lee B, Tarng Y,"Cutting-parameter selection for maximizing production rate or minimizing production cost in multistage turning operations" 
Journal of Materials Processing Technology,(2000) 105, pp: 61-66

[9] Motorcu, A,'The Optimization of Machining Parameters Using the Taguchi Method for Surface Roughness of AISI 8660 Hardened Alloy Steel," Journal of Mechanical Engineering (2010) 56,6, pp:391-401

[10] Abburi N. R., Dixit U. S.,"Multiobjective optimization of multi pass turning processes" Int. J. Adv. Manuf. Technol.,(2007), 32, pp.: 902-910

[11] Munawar M, Mufti N, and Iqbal $H$, "Optimization of Surface Finish in Turning Operation by Considering the Machine Tool Vibration using Taguchi Method," Mehran University Research Journal of Engineering \&Technology, (2012), 31, No. 1, pp: 51-58

[12] Alberti N and Perrone G,"Multi pass machining optimization by using fuzzy possibilistic programming and genetic algorithms" ProcInstn Mech. (1999),Engrs., 213 Part B, pp.:261273

[13] Abd-Rabbo, S.M., Ali, M.A., "Investigation of different approaches for the determination of optimum machining variables in turning," 7th Conference theoretical and applied mechanics, Academy of Science Research and Technology, (ASRT), (2003), pp: 163-176, Cairo, Egypt
[14] Optimization Toolbox ${ }^{\mathrm{TM}}$ User's Guide COPYRIGHT 1990-2008 by The Math Works, Inc.

[15] Shamara R, Fjalestad K, and Glemmestad B, "Optimization of Lift Gas Allocation in Gas Lifted Oil Field as Non-Linear Optimization Problem," Modeling Identification and Control, (2012) Vol 33, No. 1, pp:13-25

[16] Elkaseer A.M., Dimov S.S., Minev R. and Scholz S., "Simulation-Based Study of the $\mu$-Endmilling process." Proceedings of ICOMM, Illinois, USA, (2012)

[17] Kurdi M, Schmitz T and Haftka R," Milling optimisation of removal rate and accuracy with uncertainty: part 1: parameter selection,” Int. J. Materials and Product Technology, (2009) Vol. $\mathrm{x}$, No. $\mathrm{x}$

[18] Ebubekir Ko, "The Bees Algorithm Theory, Improvements and Applications," PhD Cardiff University (2010)

[19] Negm M," An improved version of the bees algorithm based on an adaptive learning search framework," MSc Thesis, Manufacturing Engineering Center, Cardiff University, Cardiff, United Kingdm, (2009). 